\title{
MODELING EVAPOTRANSPIRATION FOR C4 and C3 CROPS IN THE WESTERN LAKE ERIE BASIN USING REMOTE SENSING DATA
}

\author{
Y. Marambe ${ }^{1}$, A. Simic Milas, ${ }^{1, *}$ \\ ${ }^{1}$ Bowling Green State University, School of Earth, Environment and Society, Department of Geology, Bowling Green, Ohio, USA
}

KEY WORDS: Evapotranspiration, Photosynthesis, Crops, C3/C4 plants

\begin{abstract}
:
Growing monoculture impacts not just soil properties and biodiversity but also local hydrology including evapotranspiration (ET). The Midwest region of the U.S. is known for its monoculture trend by growing and producing corn, which commonly replaces other crop types. In addition to large areas covered with corn, the photosynthetic adaptations of corn, being the $\mathrm{C} 4$ crop, affects ET differently than other $\mathrm{C} 3$ crops such as soybean, wheat, and alfalfa. This study aims to model and compare ET for C3 and C4 crops using remote sensing (Sentinel2 data) and the Boreal Ecosystem Productivity Simulator (BEPS) model, modified to consider C3 and C4 crops. The study explores the ET rate trend for corn and soybean in an agriculture area situated in the Western Lake Erie Basin, where the balance between evapotranspiration, groundwater level, and surface runoff may play a role in agricultural runoff and Lake Erie's algal blooms caused by runoff pollution. The results suggest that the monthly average ET rates for both soybean (C3) and corn (C4) reach its maximum at the midto-late growing season. However, the ET rate for corn is higher than for soybean in the early season (June) (ET=121 $\mathrm{mm} \mathrm{month}^{-1}$ for corn; $\mathrm{ET}=105 \mathrm{~mm} \mathrm{month}^{-1}$ for soybean), while the ET rate for soybean becomes higher than for corn soon after (July) and becomes considerably higher in August $\left(\mathrm{ET}=181 \mathrm{~mm}\right.$ month $^{-1}$ for corn; $\mathrm{ET}=218 \mathrm{~mm}$ month $^{-1}$ for soybean). It is surmised that the higher ET rate for corn in the early growing season is due to nitrogen-based fertilizer commonly applied to corn parcels at that time, whereas soybean growth is based on biological nitrogen fixation.
\end{abstract}

\section{MANUSCRIPT}

\subsection{Introduction}

Evapotranspiration (ET) is a process of water movement through plants generated by water potential gradients between the rhizosphere, plants, and the atmosphere (Landsberg and Waring, 2016). ET affects the photosynthesis rate and, together with the carbon dioxide $\left(\mathrm{CO}_{2}\right)$ uptake, controls the primary production of crops, their vigor and yield (Kool et al., 2014; Fisher et al., 2017; Irmak, 2017). Through interactions with soil moisture, as function of soil texture and soil water holding capacity, ET controls nutrient absorption and crop growth. Nowadays, when crop management practices are designed to ensure the maximum yield to satisfy the food and energy (biofuel) requirements of the growing population, understanding and predicting crop ET is critical (Black et al., 2012; FAO, 2017). Water resource management and irrigation processes are being constantly adjusted to balance ET (Liu et al., 2003; FAO, 2016), due to the constantly changing weather and crop management practices.

The recent trend of monoculture farming affects not just soil properties and biodiversity but also local hydrology including ET. The Midwest region of the U.S. is known for its high production of corn and soybean where the monoculture trend, by growing and producing corn that replaces other crop types, has been observed in recent years. The trend is observed not just in the Midwest region but across the whole U.S. (Mladenoff et al., 2016; Gao et al., 2017). The production of corn plays an important role in the U.S. economy. The U.S. Department of Agriculture (USDA) related the trend of high corn production to ethanol, in addition to human and livestock production (USDA, 2017; USDA, 2018). The USDA estimated that corn planted in 2017 covered an area of 90.9 million acres and that the daily biofuel production in 2017 was nearly 1000 barrels per day.

In addition to larger areas covered with corn, the photosynthetic adaptations of corn, as the most widely cultivated C4 plant, affects ET differently than other, more abundant, C3 crops (e.g., soybean, wheat, and alfalfa). It is well known that $\mathrm{C} 4$ plants have their photosynthetic mechanism developed to reduce photorespiration and save water (Ajao et al., 2017) and that they are more photosynthetically active than C3 plants (Ueno, 2001; Garner et al., 2016; Ajao et al., 2017). Lundgren and Christin (2016) summarized the findings showing how the anatomical variations in $\mathrm{C} 4$ plants also exhibit more efficient uptake of $\mathrm{CO}_{2}$. Known as the ratio between primary production and transpiration, the Water Use Efficiency (WUE), which is higher in C4 plants, helps them to survive better in harsh environments (Cernusak et al., 2007). Overall, C4 plants perform better in conditions of high temperatures, with a wide range of $\mathrm{CO}_{2}$ concentrations, and in soil with poor water conditions (Powell and Still, 2009; Black et al., 2012). By contrast, $\mathrm{C} 3$ crops increase water consumption under the same conditions but their yield decreases (Leakey et al., 2009; Kumar et al., 2017).

In the present study, the Boreal Ecosystem Productivity Simulator (BEPS) model (Liu et al., 1997), modified for C3 and C4 crops in this study, is used to estimate subtle ET differences between corn (C4) and soybean (C3) using Sentinel-2 satellite data for the growing season of 2016. The aim is to explore the ET temporal trends for the two crops in an agriculture area situated within the

\footnotetext{
* Corresponding author.

E-mail addresses: asimic@bgsu.edu (A. Simic Milas), ymaramb@,bgsu.edu (Y.Marambe).
} 
Western Lake Erie Basin where the balance between evapotranspiration, groundwater level, and surface runoff may play an important role in agricultural runoff and Lake Erie's algal blooms caused by runoff pollution.

\section{METHODS}

\subsection{Study Site}

The study area is located in northwest Ohio and southeast Michigan within the Western Lake Erie Basin (WLEB) (latitude $41.78^{\circ}$, longitude -83.92). The area partially covers Lucas and Fulton counties of Ohio, and Lenawee and Monroe counties of Michigan (Figure 1). In 2016, the agricultural lands covered around $75 \%$ of the study area (USDA, 2016). The USDA's cropland classified map measured $37 \%$ of soybean, $28 \%$ of corn, $7 \%$ of wheat, and $2 \%$ of alfalfa for the same year. Besides the agricultural lands, there were some deciduous trees and grasslands. Irrigation is not a common agricultural practice in the study area and it is not considered in the present study.

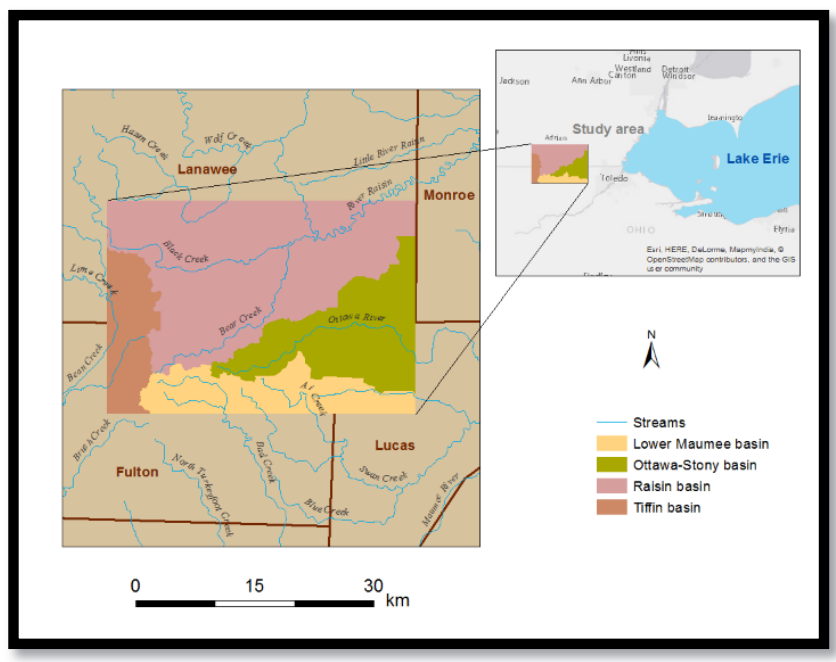

Figure 1: Study site - Agricultural lands in the Western Lake Erie Basin (WLEB)

\subsection{ET Modeling}

BEPS is a process-based physical model that simulates Net Primary Production (NPP), Gross Primary Productivity (GPP) and Evapotranspiration (ET) (Liu et al., 1997; Simic at al., 2004). BEPS incorporates all known factors that affect ET processes (Zhang et al., 2012). The model has proved its performance in different studies using various ecosystems worldwide (Liu et al., 2002; Govind et al., 2009; Zhang et al., 2012). BEPS incorporates meteorological, soil, and remote sensing data to estimate ET. Precipitation, solar radiation, maximum temperature, minimum temperature, and average relative humidity are required for the daily model simulation. Land cover (LC) data are necessary to simulate ET because of specific plant physiological parameters for each LC or crop types. Leaf area index $(L A I)$ is another important input parameter to BEPS, generated from satellite images (Liu et al., 2002; Govind et al., 2009). BEPS considers sunlit and shaded leaf areas in the photosynthesis related calculations, plant canopy structure, $L A I$, clumping index, plant physiological parameters, stomatal resistance/conductance, and plant type (Liu et al., 2002). BEPS facilitates analyses at different scales from local and regional to global levels (Liu et al., 2002). To run BEPS in this study, two land-use classes, one for $\mathrm{C} 3$ crops and another for $\mathrm{C} 4$ crops, were added and their parameters appropriately modified. Daily ET values, calculated in each run, were averaged and represented as monthly values.

\subsection{Data}

GridMET daily meteorological data sets were used in the present study (http://www.climatologylab.org/gridmet.html) with the resolution of $\sim 4-\mathrm{km} / 1 / 24^{\text {th }}$ degree. The gridMET data sets are a combination of NLDAS-2 (National Land Data Assimilation System-2) data with hourly measurements and $1 / 8^{\text {th }}$-degree grid spacing, and PRISM (Parameter-elevation Regression on Independent Slope Model) data sets with the spatial resolution of $800 \mathrm{~m}$, and monthly temporal resolution (Abatzoglou, 2011).

Available Water Holding Capacity (AWHC) data sets were collected from the Soil Survey Geographic (SSURGO) database (USDA, 2017).

Sentinel-2 satellite data were used to produce $L A I$ and LC, as input data to BEPS. Sentinel-2 images were obtained from the European Space Agency (ESA) Copernicus data hub (https://scihub.copernicus.eu/). Atmospheric corrections were performed using the Fast Line of Sight Atmospheric Analysis of Spectral Hypercubes (FLAASH), an advanced atmospheric correction model embedded in the ENVI 5.4 software (Harris Geospatial, 2017). The Sentinel-2 data were resampled to $10 \mathrm{~m}$.

LAI images were generated in accordance with the temporal resolution of Sentinel-2 data, for 10-day intervals. An empirical algorithm was used to calculate $L A I$, as given by Boegh et al. (2002). The algorithm is a widely used in-built spectral function of ENVI 5.4 (Boegh et al., 2002):

$$
L A I=(3.618 \times E V I-0.118)
$$

where $E V I=$ Enhanced Vegetation Index

According to Boegh et al. (2002), the performance of this algorithm was successful when tested over the agricultural land covers, especially over corn, winter wheat, and grassland covers.

EVI is developed by Huete et al. (2002):

$$
E V I=2.5 \times(N I R-R e d) /(N I R+6 \times \text { Red }-7.5 \times \text { Blue }+1)
$$

$E V I$ is commonly used to improve separation of vegetation signal from background signal. It also performs well in non-vegetation areas as well as in areas with high biomass. The EVI algorithm uses the blue spectral band, which is sensitive to the atmosphere (Huete et al., 2002). Sentinel 2 images were classified using the maximum likelihood image classifier, a widely used parametric classification method. 


\section{RESULTS AND DISCUSSION}

Land cover classification images have high overall accuracy $(\mathrm{OA}=95 \%$, Kappa coefficient $=0.92)$ when compared with the USDA cropland classification reference map (USDA, 2016). The accuracy for soybean and corn are $97 \%$ and $98 \%$, respectively (Figure 2). The accuracy is also high for deciduous trees and grassland as well as for other crops, which include winter wheat in June, cover crop to replace winter wheat from July - October, and perennial alfalfa.

The LAI images derived using EVI closely follow the pattern of EVI (Figure 2). Zonal statistics was used to examine LAI for different land covers. $L A I$ increases gradually for corn and more rapidly for soybean before the peak growing season in August.
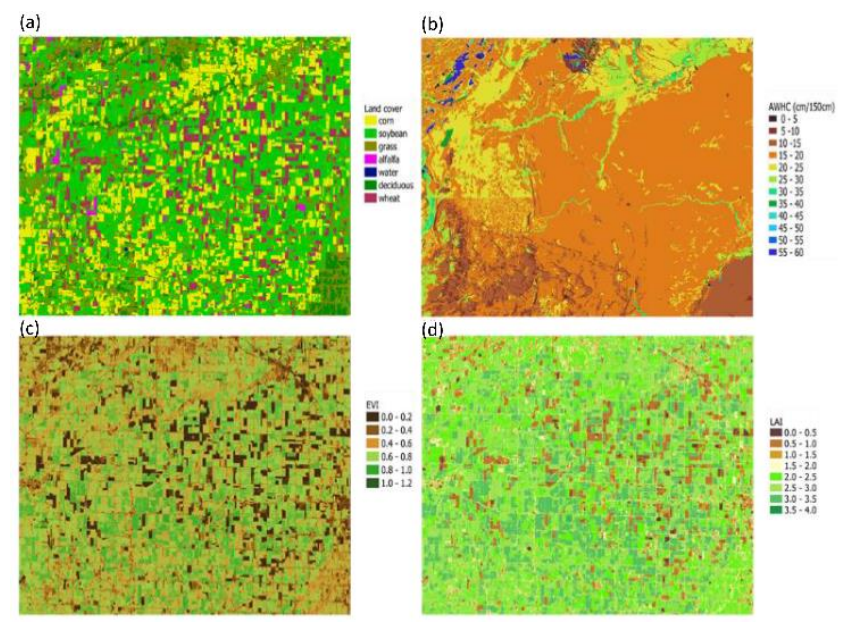

Figure 2. Input data to BEPS: a) Land cover; b) AWHC c) EVI d) $L A I$

The BEPS outputs (daily ET) averaged for each month reach their peaks in August for C4 and all C3 crops (Figures 3 and 4).

In June, the highest ET rate is observed for corn $(\mathrm{ET}=121 \mathrm{~mm}$ month $\left.^{-1}\right)$. Soybean exhibits lower ET for the same month (ET=105 $\mathrm{mm}$ month $^{-1}$ ). While the ET rate for corn is higher in the early growing season, the ET rate for soybean becomes higher in July and stays that way until the end of the season. The ET rate for soybean increases by $47 \%$ from July to August, while the rate for corn increases $24 \%$ between the two months (Figures 3 and 4 ). The cover crop on the winter wheat plots has the lowest ET rates for all months. Alfalfa is the perennial crop and has the highest ET rate in June. The lowest ET rate is observed in October for all crops, as expected.

It can be expected that corn grown as monoculture may increase the ET rate but only in the early growing season. Overall, it would decrease the ET rate under given conditions. In this preliminary study, the BEPS parameters such as stomata resistance were kept equal for soybean and corn.

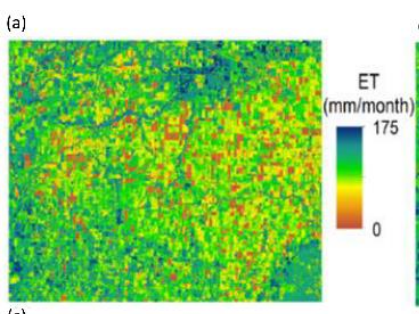

(c)
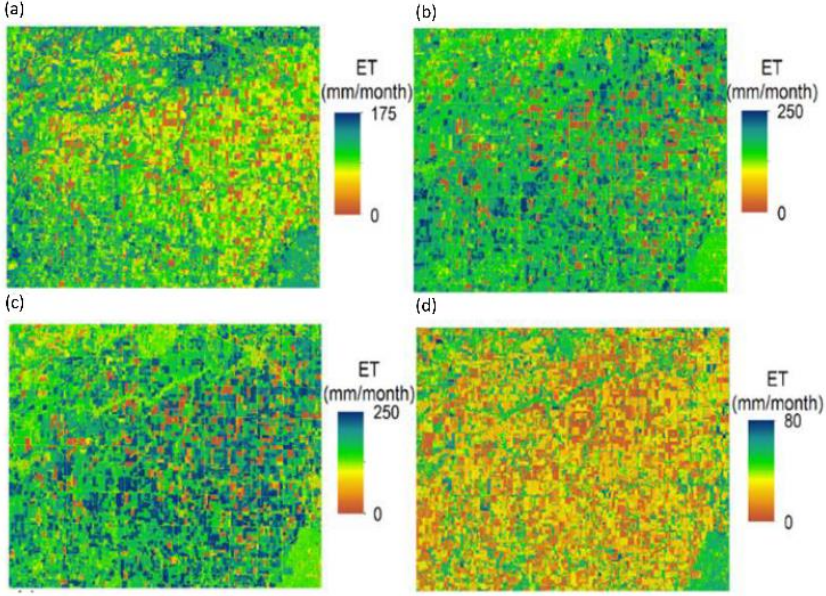

Figure 3. Spatial monthly average ET rate for: a) June; b) July; c) August; d) October 2016.

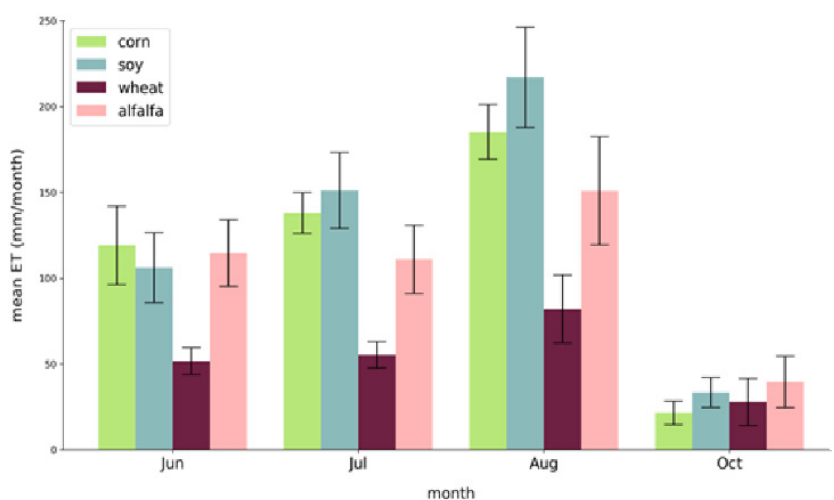

Figure 4. Monthly average ET rate for: a) June; b) July; c) August; d) October 2016.

Corn monoculture may affect the overall ET rate but most likely not considerably. The ET trend can be related to the properties of $\mathrm{C} 4$ vs. C3 plants as it is in accordance with the photosynthetic activities of corn being $\mathrm{C} 4$ and soybean being $\mathrm{C} 3$ plants. As $\mathrm{C} 4$ plants have photosynthetic mechanisms developed to reduce photorespiration and save water, it is expected that they have lower ET rate. The possible impact of the agricultural treatments on ET has not been explicitly considered in the study, but it is indirectly captured in the remote sensing derived data. It is surmised that the higher ET rate for corn in the early growing season is due to nitrogen-based fertilizer commonly applied to corn parcels at that time, whereas soybean growth is based on biological nitrogen fixation. This is in accordance with the study of Simic Milas and Vincent, 2016.

\section{CONCLUSION}

Corn has much higher yield than any other crop and it grows as a monoculture in many parts of America, especially in the Midwest. Corn is a versatile crop and it can be used for food for humans and animals, and converted into ethanol among other products. This preliminary study explored the possible impact of corn 
monoculture on evapotranspiration in an agricultural area situated within the Western Lake Erie Basin. Given that corn is the C4 crop and that other crops in the areas, such as soybean, winter wheat, and alfalfa, are C3 crops, it was hypothesized that corn monoculture might affect local evapotranspiration, which is an important hydrological parameter.

Soil properties and meteorological data, together with leaf area index and $\mathrm{C} 3 / \mathrm{C} 4$ land-use spatial data, derived using remote sensing Sentinel-2 data, were utilized in the BEPS model modified for $\mathrm{C} 3$ and $\mathrm{C} 4$ crops. It was observed that the monthly average ET rate for corn was higher in the early growing season, while the ET rate for soybean became higher in July and stayed that way until the end of the season. It is anticipated that the findings of this study could also be considered for different agricultural settings where irrigation is included in the farming practices. Global warming may restrict irrigation water resources for farmlands in the future and farmers may rely more on $\mathrm{C} 4$ crops such as corn considering its better WUE and high yield. Fu et al. (2009) and Hobbins et al. (2004) suggested the importance of soybean and corn in food production, but they also emphasized the possible 'ecohydro' impacts of these major crops, including the impact on ET.

\section{Acknowledgments}

The authors would like to thank Gang Mo from the University of Toronto, for his help with the modification of the BEPS model.

\section{References}

Abatzoglou, J.T., 2011. Development of Gridded Surface Meteorological Data for Ecological Applications and Modelling. Int. J. Climatol. 33 (1), 121-131.

Ajao, A.A., Jimoh, M.A., Saheed, S.A., 2017. Studies on Anatomical Characters Indicating C3 and C4 Photosynthetic Metabolism in the Genus Boerhavia L. (Nyctaginaceae). Taiwania. 62 (3), 265-271.

Black, E., Vidale, P.L., Verhoef, A., Santiago Vianna Cuadra, S.V., Osborne, T., Hoof, C.V.D., 2012. Cultivating C4 Crops in a Changing Climate: Sugarcane in Ghana. Environ. Res. Lett. 7 (4), 044027.

Boegh E., Soegaard H., Broge N., Hasager C., Jensen N., Schelde K.,Thomsen A., 2002. Airborne multi-spectral data for quantifying leaf area index, nitrogen concentration and photosynthetic efficiency in agriculture. Remote. Sens. Environ. 81 (2-3), 179-193.

Cernusak, L.A., Aranda, J., Marshall J.D., Winter, K., 2007. Large Variation in Whole-Plant Water-Use Efficiency among Tropical Tree Species. New Phytol. 173, 294-305.

Food and Agriculture Organization (FAO). Introduction to Evapotranspiration. Url: http://www.fao.org/docrep/X0490E/x0490e04.htm (visited on March 15 2017).

Food and Agriculture Organization (FAO), 2017. The future of food and agriculture - Trends and challenges. Url: http://www.fao.org/3/a-i6583e.pdf (visited on April 12 2017).

Fisher, J.B., Melton, F., Middleton, E., Hain, C., Anderson, M., Allen, R., McCabe, Wood, E.F., 2017. The Future of Evapotranspiration: Global Requirements for Ecosystem Functioning, Carbon and Climate Feedbacks, Agricultural
Management, and Water Resources. Water. Resour. Res. 53 (4), 2618-2626

Fu, G., Charles, S.P., Yu, J., 2009. A Critical Overview of Pan Evaporation Trends over the Last 50 Years. Clim. Change. 97, 193-214.

Gao, J., Sheshukov, A.Y., Yen, H., Kastens, J.H., Peterson, D.L., 2017. Impacts of Incorporating Dominant Crop Rotation Patterns as Primary Land Use Change on Hydrologic Model Performance. Agric. Ecosyst. Environ. 247, 33-42.

Garner, D.M.G., Mure, C.M., Yerramsetty, P., Berry, J.O., 2016. Kranz Anatomy and the C4 Pathway. DOI: https://doi.org/10.1002/9780470015902.a0001295.pub3

Govind, A., Chen, J.M., Margolis, H., Ju, W., Sonnentag, O, Giasson, M., 2009. A Spatially Explicit Hydro-Ecological Modeling Framework (BEPS-Terrainlab V2.0): Model Description and Test in a Boreal Ecosystem in Eastern North America. J. Hydrol. 367, 200-216.

Harris Geospatial, 2017. Url: https://www.harris.com/what-wedo/geospatial-solutions (visited on April 4 2017)

Hobbins, M.T., Ramirez, J.A., Brown, T.C., 2004. Trends in Pan Evaporation and Actual Evapotranspiration across the Conterminous U.S.: Paradoxical or Complementary? Geophys. Res. Lett. 31, L13503, doi:10.1029/2004GL019846.

Huete, A., Didan, K., Miura, T., Rodriguez, E.P., Gao, X., Ferreira, L.G., 2002. Overview of the Radiometric and Biophysical Performance of the MODIS Vegetation Indices. Remote Sens. Environ. 83, 195-213.

Irmak, S., 2017. Evapotranspiration Basics and Estimating Actual Crop Evapotranspiration from Reference Evapotranspiration and Crop-Specific Coefficients. Nebraska Extension-Crops and Irrigation Engineering NebGuide. Url: http://extensionpublications.unl.edu/assets/pdf/g1994.pdf

Kool, D., Agam, N., Lazarovitch, N., Heitman, J.L., Sauer, T.J., Ben-Gal, A., 2014. A Review of Approaches for Evapotranspiration Partitioning. Agric. For. Meteorol. 184, 56-70.

Kumar, V., Sharma, A., Soni, J.K., Pawar, N., 2017. Physiological Response of C3, C4 and CAM Plants in Changeable Climate. Pharma Innov. 6 (9), 70-79.

Landsberg, J., Waring, R., 2016. Water Relations In Tree Physiology: Where To From Here?. Tree Physiol, 37 (1), 18-32.

Leakey, A.D.B., Ainsworth, E.A., Bernacchi, C.J., Rogers, A., Long, S.P., Ort, D.R., 2009. Elevated $\mathrm{CO}_{2}$ Effects on Plant Carbon, Nitrogen, and Water Relations: Six Important Lessons from FACE. J. Exp. Bot. 60, 2859-2876.

Liu, J., Chen, J.M., Chillar, J., Park, W.M., 1997. A ProcessBased Boreal Ecosystem Productivity Simulator Using Remote Sensing Inputs. Remote Sens. Environ., 62, 158 175.

Liu, J., Chen, J.M., Chillar, J., Chen, W., 2002. Net Primary Productivity Mapped for Canada at 1-km Resolution. Glob. Ecol. Biogeogr. 11 (2), 15-129.

Liu, J., Chen, J.M., Chillar, J., Park, W.M.. 2003. Mapping Evapotranspiration Based On Remote Sensing: An Application to Canada Landmass. Water Resour., 39 (7), 1189. 
Lundgren, M.R., Christin, P.A., 2016. Despite Phylogenetic Effects, $\mathrm{C}_{3}-\mathrm{C}_{4}$ Lineages Bridge the Ecological Gap to $\mathrm{C}_{4}$ Photosynthesis. J. Exp. Bot. 68 (2), 241-254.

Mladenoff, D.J., Sahajpal, R., Johnson, C.P., Rothstein, D.E., 2016. Recent Land Use Change to Agriculture in the U.S. Lake States: Impacts on Cellulosic Biomass Potential and Natural Lands. PLoS ONE, 11 (2). https://doi.org/10.1371/journal.pone.0148566.

Powell, R.L., Still, C.J., 2009. Biogeography of C3 and C4 vegetation in South America. Anais XIV Simpósio Brasileiro de Sensoriamento Remoto, Natal, Brasil, INPE, 2935-2942.

Simic A., Chen J.M., Liu J., Csillag F., 2004. Spatial scaling of net primary productivity using subpixel information. Remote Sens. Environ. 93, 246-258.
Simic Milas, A, Vincent, K., R., 2016. Monitoring Landsat vegetation indices for different crop treatments and soil chemistry. Int. J. Remote Sens. 38 (1), 141-160. DOI: $10.1080 / 01431161.2016 .1259680$.

Ueno, O., 2001. Environmental Regulation of C3 and C4 Differentiation in The Amphibious Sedge Eleocharisvivipara1. Plant Physiol. 127, 1524-1532.

USDA. (2016). CropScape- Cropland Data Layer. Url: https://nassgeodata.gmu.edu/CropScape/ (visited on March 3 2017).

USDA. (2017). National Agriculture Statistic Service. Url: https://www.nass.usda.gov/Newsroom/2018/01 12 2018.p hp (visited on April 3 2017).

Zhang, F, Chen, J.M., Chen, J., Gough, C.M., Martin, T.A., Dragoni, D., 2012. Evaluating Spatial and Temporal Patterns of MODIS GPP over the Conterminous U.S. against Flux Measurements and a Process Model. Remote Sens. Environ. 124, 717-729. 